\title{
Diagnosis of Brugada Syndrome, a Rare Inherited Arrhythmogenic Disorder
}

\author{
Juwairiya Syed Iqbaluddin Fathima Murthuza Sumaiya lqbal \\ Dubai Medical College, Dubai, UAE
}

\section{Keywords}

Brugada syndrome - Genetic disorder - Ajmaline test .

Electrophysiology study Sudden cardiac death

\begin{abstract}
Brugada syndrome $(\mathrm{BrS})$ is a rare, autosomal dominant genetic disorder with mutation in the SCN5A gene. It is associated with an increased risk of arrhythmias and sudden cardiac death. BrS can be diagnosed by characteristic electrocardiogram (ECG) findings and significant events, such as syncope, palpitations, nocturnal respiratory agonia, and family history of sudden cardiac death below the age of 45 years. Special investigations, such as electrophysiology study, ajmaline provocation test, and genetic testing, play an important role in its diagnosis. This case report describes a patient who presented with chest pain and dizziness along with a positive family history of sudden cardiac deaths below the age of 45 years. He was discovered to have type 2 Brugada pattern on ECG, and by ajmaline provocation test, the type 1 pattern was unmasked, which established a definitive diagnosis of BrS. The patient was then advised for an implantable cardioverter-defibrillator. This case highlights the need for physicians to be competent in identifying patients with $\mathrm{BrS}$ in order to provide the necessary management and prevent fatal outcomes.

(c) 2020 The Author(s)

Published by S. Karger AG, Basel
\end{abstract}

\section{Introduction}

Brugada syndrome $(\mathrm{BrS})$ is named by the Spanish cardiologists Pedro Brugada and Josep Brugada who reported it as a distinct clinical syndrome in 1992 [1]. The worldwide prevalence of $\mathrm{BrS}$ was estimated at $0.01 \%$ and is highly prevalent in Southeast Asia [2]. BrS is an autosomal dominant genetic disorder. Incomplete penetrance is frequent in families, and the disease can be sporadic in up to $60 \%$ of patients. $S C N 5 A$, which was identified as the first BrS-associated gene, has emerged as the most common gene associated with this condition. $\mathrm{BrS}$ is also characterized by abnormal findings on the surface electrocardiogram (ECG) in conjunction with an increased risk of ventricular tachyarrhythmias and sudden cardiac death [3]. BrS is associated with other conduction abnormalities, including first-degree atrioventricular block, intraventricular conduction delay, and sick sinus syndrome. There is an increased risk of atrial arrhythmias, most notably atrial fibrillation, which in turn has been associated with increased disease severity and a higher risk of ventricular fibrillation. Given its potential consequences, physicians must be familiar with the electrocardiographic features of BrS. The following case report describes the importance of taking a detailed history and performing the necessary workup in order to diagnose BrS in a young male.

\begin{tabular}{ll}
\hline KARGER & ( 2020 The Author(s) Karger \\
& Published by S. Karger AG, Basel Open cacess \\
karger@karger.com & This article is licensed under the Creative Commons Attribution- \\
www.karger.com/dmj & NonCommercial-NoDerivatives 4.0 International License (CC BY- \\
NC-ND) (http://www.karger.com/Services/OpenAccessLicense). \\
Usage and distribution for commercial purposes as well as any dis- \\
tribution of modified material requires written permission.
\end{tabular}

Juwairiya Syed Iqbaluddin

Dubai Medical College for Girls

PO Box 20170, Al Muhaisanah 1, Al Mizhar

Dubai (UAE)

juw.iqbal@gmail.com 


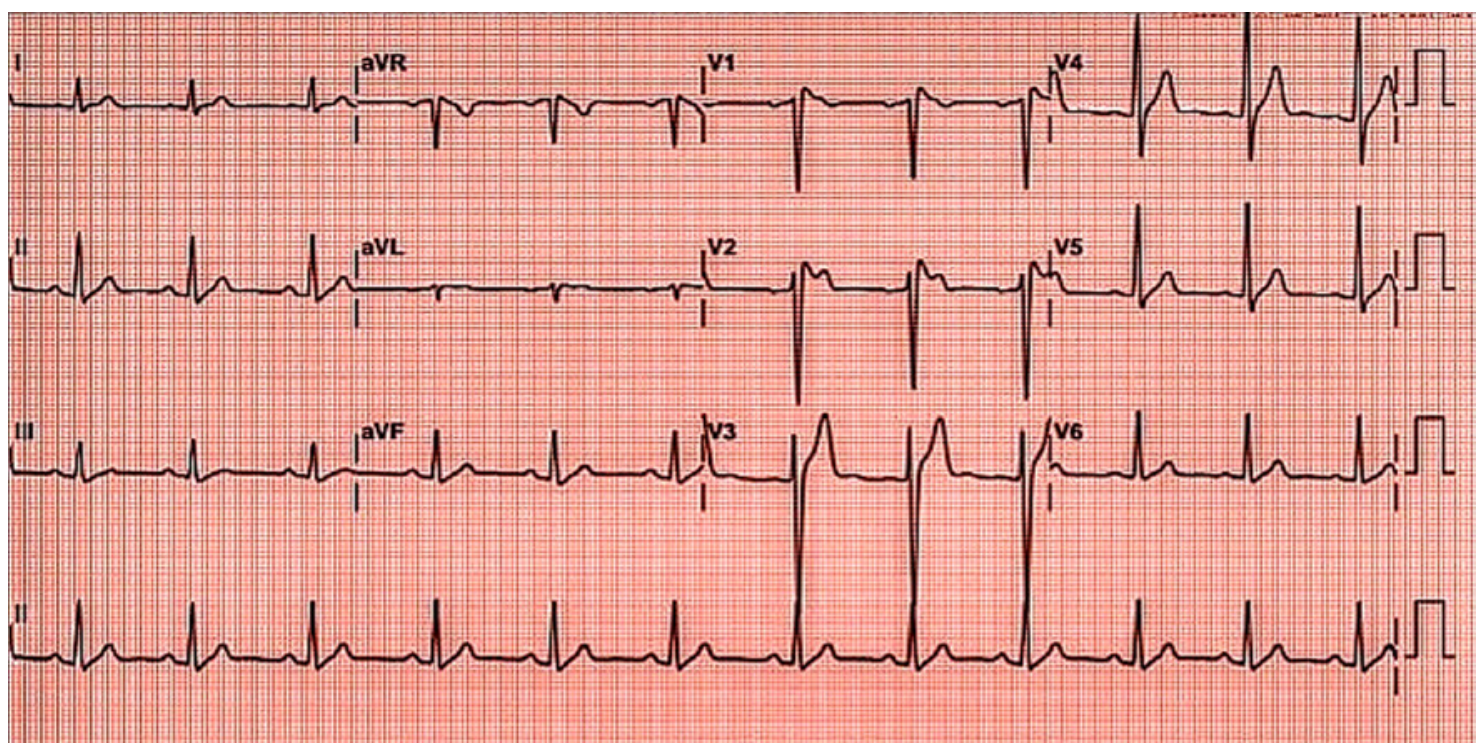

Fig. 1. Type 2 Brugada pattern during first encounter.

\section{Case Report}

A 24-year-old Indian male, a known case of hypertension, with no compliance to medication, presented to the Emergency Department with chest pain and dizziness. He presented early in the morning with sharp pricking, moderate-intensity, left-sided chest pain which started gradually and had been progressively increasing in intensity with radiation to the upper back and associated dizziness. The pain exacerbated on exercise but was present even at rest. He had no complaints of palpitations, dyspnea, syncope, leg swelling, or vomiting. He had been having intermittent episodes of chest pain for the past 3 years, which used to settle within a few minutes. Dizziness had been present on and off for a year as well, occurring twice a week and lasting for a few minutes. It occurred more frequently when he was stressed and was associated with headaches, darkening of vision, and chest pain. Headache was generalized but more at the occipital region and pressuring in nature. It often occurred following an episode of dizziness without any radiation. There was no history of vomiting, tinnitus, and loss of weight or appetite.

Three-generation family history was looked into and showed that his brothers died at an early age. One died at 3 days of age due to an unknown cause and the other died at 14 years of age due to heart failure. His paternal aunt died at 40 years of age due to cardiac arrest.

He was a known case of hypertension for 3 years with baseline blood pressure of $160 / 90 \mathrm{~mm} \mathrm{Hg}$ and not compliant with medicines due to financial reasons. He underwent an eardrum repair surgery and appendectomy in 2014 and 2017, respectively. He did not take any medicines and had no known allergies. He was unmarried, worked as a cleaner, and was a nonsmoker and occasional drinker. On clinical examination, the patient was lying comfortably on the bed, oriented, alert, and not in distress. He had a temperature of $36.4{ }^{\circ} \mathrm{C}$, respiratory rate of $21 / \mathrm{min}$, pulse rate of $90 /$ $\mathrm{min}$, and blood pressure of $162 / 101 \mathrm{~mm} \mathrm{Hg}$. His pulse was of reg- ular rhythm, character, and volume. He had no evidence of jugular venous distention, visible precordial pulsations, hepatomegaly, or pedal edema. Auscultation of his chest revealed normal S1, S2, and no other added sounds. Other system examinations were unremarkable.

\section{Investigation and Management}

A 12-lead ECG on arrival showed normal sinus rhythm with the presence of saddle back ST-T wave configuration in V2, which was consistent with type $2 \mathrm{BrS}$ pattern as well as incomplete right bundle branch block (Fig. 1). Complete blood count revealed microcytic hypochromic red blood cells with hemoglobin of $14.9 \mathrm{~g} /$ $\mathrm{dL}$, white blood cell count of $7.9 \times 10^{3} / \mu \mathrm{L}$, and platelets of $209 \times$ $10^{3} / \mu \mathrm{L}$. Electrolytes, thyroid function tests, random blood glucose, $\mathrm{HbA1c}$, urea, creatinine, creatine kinase isoenzyme MB, NT-pro$\mathrm{BNP}$, and troponin T values were within normal limits. HIV 1 and 2 antigen and antibody and hepatitis B surface antigens were nonreactive. His lipid profile revealed elevated triglycerides of $225 \mathrm{mg} /$ $\mathrm{dL}$ and a low high-density lipoprotein of $40 \mathrm{mg} / \mathrm{dL}$. Chest X-ray was unremarkable. Computed tomography of the brain was normal with no evidence of infarct or intracerebral/extracerebral bleed. Transthoracic echocardiogram was done to rule out structural causes. It showed normal cardiac anatomy and function.

Lisinopril $5 \mathrm{mg}$ was administered in the Emergency Department, and the patient was admitted to the Cardiology Ward to further evaluate the suspicion for BrS. Ajmaline provocation test was conducted by infusing ajmaline at a rate of $1 \mathrm{mg} / \mathrm{min}$. The resuscitation equipment and defibrillator were kept ready to be used in the event of a cardiac arrest. ECG was monitored and 12-lead ECG was printed every $1 \mathrm{~min}$. At $5 \mathrm{~min}$, ECG showed classical type 1 Brugada pattern (Fig. 2), and the test was terminated. He was closely monitored for another $90 \mathrm{~min}$ for the occurrence of any life-threatening arrhythmias. However, he remained asymptomatic and hemodynamically stable, and the ECG gradually settled back to type 2 pattern. 


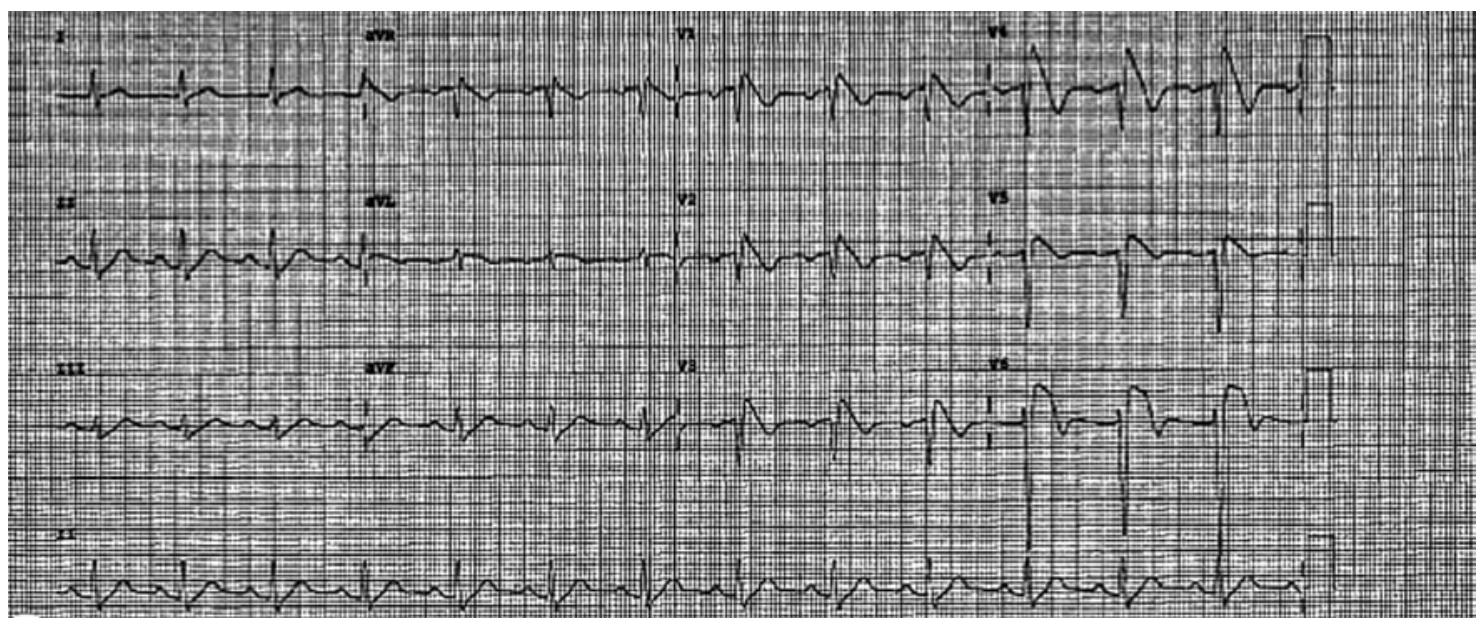

Fig. 2. Conversion of type 2 Brugada pattern to type 1 after ajmaline test.

An implantable cardioverter-defibrillator along with a followup in the clinic was planned for the management; however, the patient refused due to financial reasons.

He was then counselled about avoiding the conditions that can trigger arrhythmias. He was advised to avoid hot showers and steam bath, to treat fever promptly with antipyretics, avoid excessive alcohol intake, and was also provided with the list of medications that should be avoided.

\section{Discussion}

Individuals with $\mathrm{BrS}$ may experience ventricular arrhythmias, syncope, and nocturnal agonal respiration or may be asymptomatic. The severity of symptoms varies from person to person. There are some known triggers for BrS like fever, cocaine, and sodium-blocking drugs. Another specific presentation seen in $\mathrm{BrS}$ is sudden unexpected nocturnal death syndrome and sudden infant death syndrome, which is the death of a child within the first year of life without an identifiable cause [1].

Patients with typical ECG features who are asymptomatic and have no other clinical criteria are said to have the Brugada pattern. Patients with typical ECG features who have experienced sustained ventricular tachyarrhythmia, or who have one or more of the other associated clinical criteria, are said to have BrS [4].

Three ECG patterns of ST segment elevation have been associated with BrS. Type 1 displays $\geq 2 \mathrm{~mm}$ of downsloping or cove-shaped ST segment elevation followed by a negative $\mathrm{T}$ wave in the right precordial leads. Type 2 has $\geq 2 \mathrm{~mm}$ of ST elevation at the terminal por- tion of the ST segment, with a positive T wave that creates a saddleback appearance, and type 3 may have either cove-shaped or saddleback ST segment elevation with $<1 \mathrm{~mm}$ magnitude of elevation at the terminal portion.

Definitive diagnosis of $\mathrm{BrS}$ requires the presence of a type 1 ECG pattern or conversion of a type 2 or type 3 pattern to type 1 following provocation testing with a sodium channel blocker, plus one of the following: documented ventricular fibrillation, self-terminating polymorphic ventricular tachycardia, family history of sudden cardiac death at age $<45$ years, type 1 ECG pattern in a family member, electrophysiological induction of ventricular tachycardia, unexplained syncope felt consistent with a tachyarrhythmia, or nocturnal agonal respirations [5].

In our case, the patient complained of chest pain associated with dizziness, and ECG showed type 2 Brugada pattern in V2 with associated incomplete right bundle branch block. Upon ajmaline provocation test, the type 2 pattern was converted to a type 1 Brugada pattern. This characteristic conversion of the ECG pattern along with the positive family history of sudden cardiac death below the age of 45 years indicated a definitive diagnosis of $\mathrm{BrS}$ in this patient. An implantable cardioverter-defibrillator would be the best management for this patient.

Screening his family members with ECG and genetic testing is recommended to identify the positive cases, and even if they are asymptomatic, this would help in determining who would require counselling on the precautionary methods and would require close follow-up. 


\section{Conclusion}

BrS has specific clinical characteristics and can be diagnosed with a thorough history, ECG, and relevant investigations. This case highlights the need for physicians to be competent in identifying high-risk patients with BrS to prevent the risk of sudden cardiac death and lifethreatening arrhythmias.

\section{Acknowledgement}

We would like to thank Dr. G.A.H.R. and Dr. S.M.A. for their valuable contribution throughout.

\section{Statement of Ethics}

Patient consent for publication was obtained from the patient.

\section{Disclosure Statement}

The author(s) declared no potential conflicts of interest with respect to the research, authorship, and/or publication of this article.

This case was presented as a poster "Presentation of Brugada Syndrome in a Young Male" (unpublished) at the 3rd Emirates Family Medicine Society Congress, January 9-11, 2020, Dubai, United Arab Emirates.

\section{Funding Sources}

The authors have not declared a specific grant for this research from any funding agency in the public, commercial, or not-forprofit sectors.

\section{Author Contributions}

All authors were involved in the acquisition and interpretation of the data, the article's conception and design, and the final approval of the version to be published.

\section{References}

1 NORD (National Organization for Rare Disorders). Brugada Syndrome. Available from: https://rarediseases.org/rare-diseases/brugada-syndrome

2 Rattanawong P, Vutthikraivit W, Sukhumthammarat W, Putthapiban P, Ngarmukos T. Worldwide prevalence of Brugada syndrome: A systematic review and meta-analysis. J Am Coll Cardiol. 2017 Mar;69(11 suppl).
3 Brugada J, Campuzano O, Arbelo E, Sarquella-Brugada G, Brugada R. Present Status of Brugada Syndrome: JACC State-of-the-Art Review. J Am Coll Cardiol. 2018 Aug;72(9): 1046-59.

4 Harris CL, Greenberg YJ, Yang F, Shani J, Shetty VS. Brugada Syndrome: A Delayed and Atypical Presentation. Ann Clin Case Rep. 2019;4:1755. Available from: http://www. anncaserep.com/pdfs_folder/accr-v4-id1755. pdf
5 Antzelevitch C, Brugada P, Borggrefe M, Brugada J, Brugada R, Corrado D, et al. Brugada syndrome: report of the second consensus conference: endorsed by the Heart Rhythm Society and the European Heart Rhythm Association. Circulation. 2005 Feb;111(5):65970. 